\title{
Recent incidence trend of elderly patients with glioblastoma in the United States, 2000-2017
}

\author{
Boran Chen ${ }^{1,2+}$, Chaoyue Chen ${ }^{1,3+}$, Yang Zhang ${ }^{1,2}$ and Jianguo $\mathrm{Xu}^{1 *}$ (D)
}

\begin{abstract}
Background: The incidence of glioblastoma increases significantly with age. With the growing and aging population, there is a lack of comprehensive analysis of recent glioblastoma incidence trend in the United States. This study aims to provide in-depth description of the patterns of incidence trends and to examine the age-periodcohort effects to the trends of glioblastoma specific to elderly patients.

Methods: The incidence rates were age-adjusted and reported per 100,000 population. We calculated the annual percent change (APC) in incidence using the Joinpoint Regression Program and conducted an age-period-cohort analysis of elderly glioblastoma reported between 2000 and 2017 to the Surveillance Epidemiology and End Results (SEER) 18 registry database.

Results: The overall incidence rate of elderly patients with glioblastoma was 13.16 per $100,000(95 \% \mathrm{Cl}, 12.99-$ 13.32) from 2000 to 2017. Non-Hispanic whites (20,406, 83.6\%) made up the majority. The incidence rate of male was about 1.62 times that of female. The trend of incidence remained stable and there was a non-significant increasing tendency for all elderly patients (APC $0.3,95 \% \mathrm{Cl},-0.1$ to $0.7, p=0.111$ ). There was a significantly increasing incidence trend for non-Hispanic white (APC 0.6, 95\% Cl, 0.2 to 1.1, $p=0.013$ ), supratentorial location (APC 0.7, 95\% Cl, 0.2 to 1.3, $p=0.016$ ), tumor size $<4 \mathrm{~cm}$ (APC 2.5, 95\% Cl, 1.4 to 3.6, $p<0.001$ ), and a significantly decreasing trend for overlapping/NOS location (APC $-0.9,95 \% \mathrm{Cl}_{1}-1.6$ to $-0.2, p=0.012$ ), and unknown tumor size (APC $-4.9,95 \% \mathrm{Cl},-6.6$ to $-3.3, p<0.001$ ). The age-period-cohort analysis showed the effect of age on incidence trends ( $p<0.001$, Wald test), while did not indicate the period and cohort effects of the incidence trends of glioblastoma ( $p=0.063$ and $p=0.536$, respectively, Wald test).

Conclusion: The overall incidence of glioblastoma in the elderly population remained stable between 2000 and 2017. Period and cohort effects were not evident in the trend of glioblastoma incidence. Future population-based studies exploring the difference in the trend of glioblastoma incidence by specific molecular subgroups are warranted to further our understanding of the etiology of glioblastoma.
\end{abstract}

Keywords: Glioblastoma, Elderly, Age-adjusted incidence rate, Annual percentage change, SEER, Join-point analysis, Age-period-cohort analysis

\footnotetext{
* Correspondence: drjianguoxu@gmail.com

${ }^{+}$Boran Chen and Chaoyue Chen contributed equally to this work.

'Department of Neurosurgery, West China Hospital, Sichuan University, West

China Hosptial, No. 37, GuoXue Alley, Chengdu 610041, People's Republic of

China

Full list of author information is available at the end of the article
}

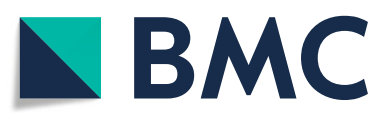

(c) The Author(s). 2021 Open Access This article is licensed under a Creative Commons Attribution 4.0 International License, which permits use, sharing, adaptation, distribution and reproduction in any medium or format, as long as you give appropriate credit to the original author(s) and the source, provide a link to the Creative Commons licence, and indicate if changes were made. The images or other third party material in this article are included in the article's Creative Commons licence, unless indicated otherwise in a credit line to the material. If material is not included in the article's Creative Commons licence and your intended use is not permitted by statutory regulation or exceeds the permitted use, you will need to obtain permission directly from the copyright holder. To view a copy of this licence, visit http://creativecommons.org/licenses/by/4.0/ The Creative Commons Public Domain Dedication waiver (http://creativecommons.org/publicdomain/zero/1.0/) applies to the data made available in this article, unless otherwise stated in a credit line to the data. 


\section{Background}

Glioblastoma is the most common and aggressive primary central nervous system tumor with an age-adjusted incidence rate of 3.22 per 100,000 population, which accounts for $57.3 \%$ of all gliomas and $48.3 \%$ of all malignant brain tumors [1]. The incidence of glioblastoma increases significantly with age and the median age at diagnosis is 65 years [1, 2]. Patients with glioblastoma have constantly poor prognosis over the past decades with a median survival of less than 2 years, despite therapeutic advances $[3,4]$. The landmark randomized controlled trial presented by Stupp et al. suggested that patients with glioblastoma may benefit from radiotherapy with concomitant temozolomide followed by six cycles of temozolomide [4]. However, this trial only did not include elderly patients. Advanced age is a wellestablished negative prognostic factor $[5,6]$. The median survival is less than 10 months among elderly patients with short-course radiotherapy plus temozolomide, according to a phase 3 randomized controlled trial [7]. Elderly patients with glioblastoma have worse prognosis and are therefore an important subgroup. However, limited studies have focused on the incidence trend of elderly glioblastoma. Dobes et al. reported an increasing incidence of glioblastoma in patients aged over 65 years from 2000 to 2008 in Australia with an annual percentage change (APC) of 3.0 (95\% confidence interval [CI], 0.5-5.6) [8]. Korja et al. reported increased proportion (from 24 to $27 \%$ ) of patients aged over 70 years with glioblastoma between 2000 and 2013 in Finland [9]. The Central Brain Tumor Registry of the US (CBTRUS) report 2019 provided incidence rates and incidence trends of glioblastoma by age group (0-14 years, $15-39$ years, and $40+$ years) [1]. It exists a vacancy in the incidence trend of patients with glioblastoma aged 65 years or older in CBTRUS report 2019. Hence there is a lack of comprehensive analysis of recent incidence trend of elderly patients with glioblastoma in the subsequent period and in the United States. Given the considerable proportion of elderly glioblastoma patients, the worse outcome of the elderly population, and the paucity of comprehensive investigation of trends for this important subgroup, we aim to conduct this study to provide in-depth description of the patterns of incidence trends and to examine the age-period-cohort effects to the trends of glioblastoma specific to elderly patients.

\section{Methods}

\section{Data sources and study cohort}

Data were derived from the Surveillance Epidemiology and End Results (SEER) 18 registry database, which consists of cancer registries from 18 geographic areas, covering approximately $28 \%$ of the US population. In this study, patients aged over 65 years with a diagnosis of glioblastoma, according to the International Classification of Diseases for Oncology, Third Edition (ICD-O-3) histology codes 9440-9442 from 2000 to 2017 were included. Demographic and tumor characteristics of included patients were obtained. Demographic characteristics included gender, race, calendar year of diagnosis, and age at diagnosis. Race was categorized into non-Hispanic White, non-Hispanic Black, Hispanic, Asian/Pacific Islander (API), and American Indian/Alaskan Native (AIAN). Age at diagnosis was grouped as 65-69 years, 70-74 years, 7579 years, $80-84$ years, and $85+$ years. Tumor characteristics included ICD-O-3 histologic type, tumor location, and tumor size. Histologic types were classified as 9440/3-glioblastoma, NOS, 9441/3-giant cell glioblastoma, and 9442/ 3 -gliosarcoma. The topography of tumor was divided into supratentorial (ICD-O-3 site codes C710-C714), infratentorial (C716-C717), and overlapping/NOS (C715, C718C719). Tumor sizes were categorized into $<4 \mathrm{~cm}, \geq 4 \mathrm{~cm}$, and unknown, according to Collaborative Stage Tumor Size. However, documentation of tumor size was only accessible for records between 2004 and 2015.

\section{Statistical analysis}

Incidence rate, incidence rate ratio (IRR) and other relevant statistics were calculated using SEER*Stat (version 8.3.8, https://seer.cancer.gov/seerstat/). Figures were generated using $\mathrm{R}$ software (version 3.6.3). The incidence rates were age-adjusted and standardized to the 2000 US population, and reported per 100,000 population with 95\% CI. The age-adjusted rate for an specific age group which comprised of the age $\mathrm{x}$ through $\mathrm{y}$ is calculated using the following formula (https://seer.cancer.gov/ seerstat/tutorials/aarates/definition.html):

$$
\begin{aligned}
& \text { Age adjusted rate }_{x-y} \\
& \qquad=\sum_{i=x}^{y}\left[\left(\frac{\text { count }_{i}}{\text { population }_{i}}\right) \times 100,000 \times\left(\frac{\text { standard population }_{i}}{\sum_{j=x}^{y} \text { standard population }_{j}}\right)\right]
\end{aligned}
$$

Joinpoint Regression Program software (version 4.8.0.1, https://surveillance.cancer.gov/joinpoint/) was used to calculate APC to quantify the trends of incidence across the years studied with the simplest joinpoint model. Joinpoint Regression Program establishes models with minimum to maximum number, which are supplied by the user, of join-points and uses the Monte Carlo Permutation method to test whether an apparent change in trends is statistically significant [10]. In this study, the minimum number and maximum number of join-points were set to 0 and 3, respectively. APC by gender, race, age at diagnosis, histological type, tumor location, and tumor size was analyzed. In order to ensure that the statistical analyses were sufficiently stable, group-specific data with a sample size less than 50 were excluded from the analysis. 
Age-period-cohort models were used to investigate the effects of age, period (year of diagnosis), and cohort (year of birth) on the change trends of glioblastoma incidence. The model was fitted to the crude incidence rates using the age-period-cohort analysis web tool developed by Rosenberg et al. [11]. Age was grouped into 11 twoyear intervals $(65-66,67-68, \ldots 83-84,85+$ years). Year of diagnosis was grouped into 9 two-year categories (2000-2001, 2002-2003 ... 2014-2015, 2016-2017). Cohort was indexed by midyear of birth $(1915,1917$... $1949,1951)$. The reference age, period and cohort were defined as the median of each range. Five age-periodcohort parameters and functions were calculated and presented in the study, including net drift, local drift, longitudinal age curve, period rate ratios (RR), and cohort RR [11]. Net drift is the analog of estimated APC of incidence rates. Local drift represents the estimated APC over time specific to age group. Longitudinal age curve depicts the longitudinal age-specific and cohort-specific rates adjusted for period deviations, which is generally considered superior to a cross-sectional age curve in assessing age effects [12]. Period RR and cohort RR are ratios of age-specific rates in each calendar period relative to the reference period (herein 2008-2009) and in each birth cohort relative to the reference cohort (herein the 1933 cohort), respectively.

\section{Results}

\section{Demographic and tumor characteristics}

Of the 24,417 elderly patients in the SEER 18 registry database identified by the three specific ICD-O-3 codes from 2000 to 2017, non-Hispanic whites (20,406, 83.6\%) made up the majority. The overall incidence rate of elderly patients with glioblastoma was 13.16 per 100,000 population (95\% CI, 12.99-13.32) from 2000 to 2017. The incidence rate of male was about 1.62 times that of female (16.85 [95\% CI, 16.57-17.14] vs 10.39 [95\% CI, 10.20-10.59] per 100,000 population). Table 1 shows detailed patient characteristics and related incidence rates.

\section{Comparison of glioblastoma incidence between the elderly and the young}

Figure 1a demonstrates the incidences of glioblastoma in the elderly ( $\geq 65$ years) and in the young ( $<65$ years) from 2000 to 2017. The overall incidence of glioblastoma in the young was 1.76 per 100,000 population $(95 \% \mathrm{CI}$, $1.70-1.74)$. The incidence trend of glioblastoma in the young remained stable between 2000 to 2017 (APC 0.0, $95 \% \mathrm{CI},-0.2$ to $0.3, p=0.850$ ). Compared with the young, the elder had approximately 8 -fold the risk of glioblastoma. The incidence of glioblastoma in the elderly reached lowest in 2006 (Incidence rate 11.97 per 100,000 population, $95 \% \mathrm{CI}, 11.28-12.69$ ) and peaked in 2009 (Incidence rate 13.98 per 100,000 population, 95\%
Table 1 Age-adjusted incidence of demographic and tumor characteristics of elderly patients with glioblastoma: The SEER 18 registry database, 2000-2017

\begin{tabular}{lll}
\hline Characteristics & $\begin{array}{l}\text { No. of } \\
\text { patients(\%) }\end{array}$ & $\begin{array}{l}\text { Age-adjusted incidence } \\
\text { rate(95\% Cl) }\end{array}$ \\
\hline $\begin{array}{l}\text { Overall } \\
\text { Gender }\end{array}$ & $24,417(100)$ & $13.16(12.99-13.32)$ \\
$\quad$ Male & $13,456(55.1)$ & $16.85(16.57-17.14)$ \\
$\quad$ Female & $10,961(44.9)$ & $10.39(10.20-10.59)$ \\
Race & & \\
$\quad$ Non-Hispanic White & $20,406(83.6)$ & $15.10(14.89-15.31)$ \\
Non-Hispanic Black & $1089(4.5)$ & $6.92(6.51-7.35)$ \\
Hispanic & $1900(7.8)$ & $10.58(10.11-11.08)$ \\
API & $927(3.8)$ & $5.90(5.52-6.29)$ \\
AIAN & $61(0.3)$ & $5.52(4.20-7.14)$
\end{tabular}

Age at diagnosis, years

$\begin{array}{lll}65-69 & 6738(27.6) & 11.67(11.39-11.95) \\ 70-74 & 6287(25.7) & 14.12(13.77-14.47) \\ 75-79 & 5412(22.2) & 15.47(15.06-15.89) \\ 80-84 & 3700(15.2) & 14.24(13.78-14.70) \\ \geq 85 & 2280(9.3) & 9.19(8.81-9.57)\end{array}$

Histologic type

Glioblastoma, NOS

Giant cell glioblastoma

23,762 (97.3)

$12.80(12.64-12.97)$

Gliosarcoma

$172(0.7)$

$0.09(0.08-0.11)$

$483(2.0)$

$0.26(0.24-0.28)$

Tumor location

Supratentorial

Frontal

$18,089(74.1)$

$9.74(9.60-9.89)$

Temporal

$6220(25.5)$

$3.34(3.26-3.43)$

Parietal

$6059(24.8)$

$3.27(3.19-3.35)$

Occipital

$3911(16.0)$

$2.11(2.04-2.17)$

Infratentorial

$1148(4.7)$

$0.62(0.59-0.66)$

Overlapping/NOS

$195(0.8)$

$0.11(0.09-0.12)$

$6133(25.1)$

$3.31(3.22-3.39)$

Tumor size, $\mathrm{cm}^{\mathrm{a}}$

$\begin{array}{lll}<4 & 5082(30.7) & 2.73(2.65-2.81) \\ \geq 4 & 8387(50.7) & 4.51(4.42-4.61) \\ \text { Unknown } & 3058(18.5) & 2.47(2.38-2.56)\end{array}$

Abbreviations: $\mathrm{Cl}$ confidence interval, API Asian/Pacific Islander, AIAN American Indian/Alaskan Native, NOS not otherwise specified

${ }^{a}$ Data are only documented between 2004 and 2015

CI, 13.25-14.73). The trend of incidence in the elderly also remained stable and there was a non-significant increasing tendency (APC 0.3, 95\% CI, -0.1 to $0.7, p=$ $0.111)$.

Incidence trends of elderly glioblastoma by gender, race and age at diagnosis

Figure $1 \mathrm{~b}$ shows the incidence of male and female patients aged over 65 years with glioblastoma across the 


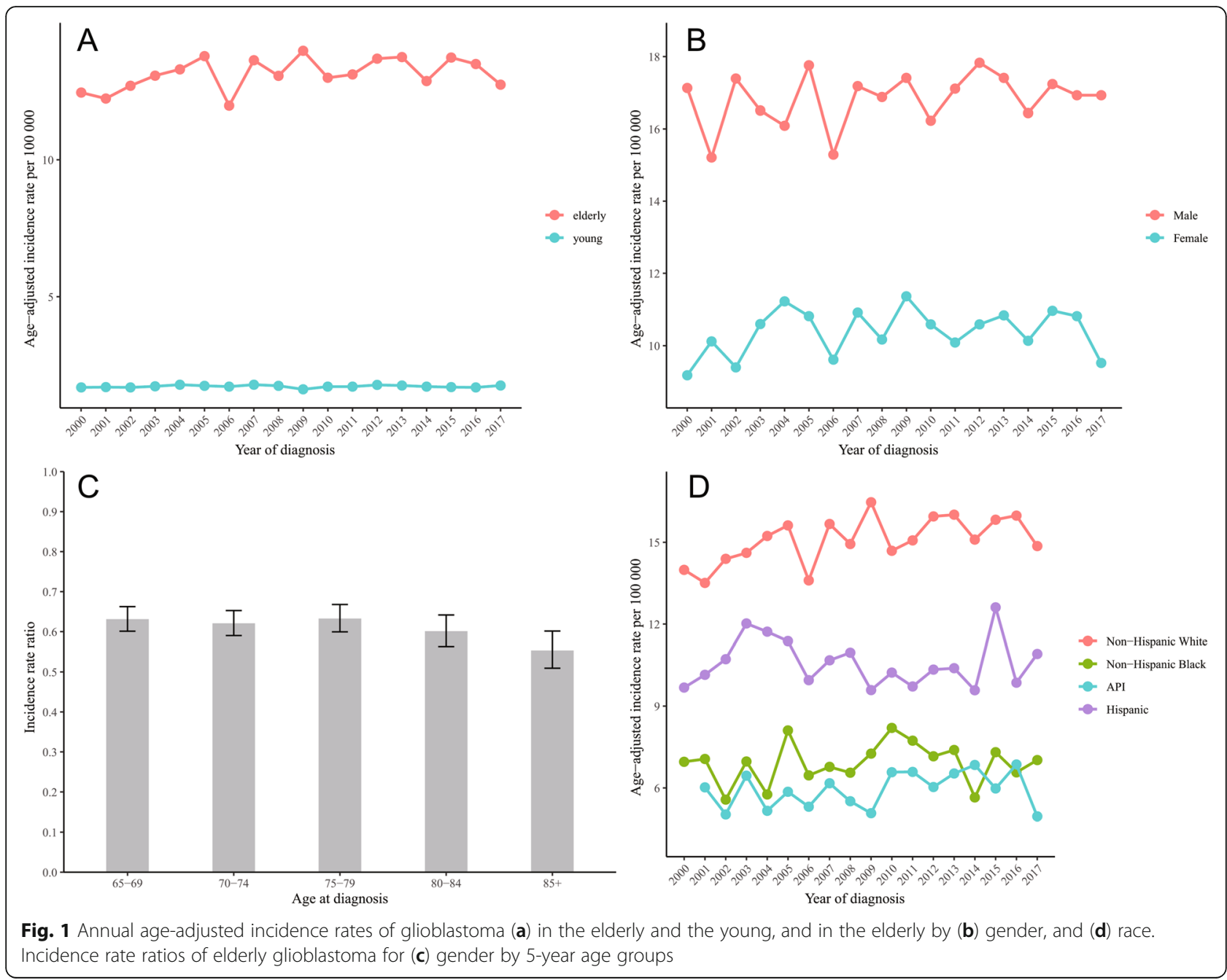

18-year study period. The trend of incidence remained stable for both male patients (APC 0.2, 95\% CI, -0.2 to $0.6, p=0.272$ ) and female patients (APC 0.2, 95\% CI, 0.4 to $0.8, p=0.402$ ) (Fig. $1 \mathrm{~b}$, Table 2). The IRRs of female to male patients stratified by age at diagnosis are displayed in Fig. 1c. Female to male IRR ranged from 0.55 to 0.63 and was lowest in $85+$ years group (Fig. 1c).

Incidence rates of non-Hispanic white patients were higher than that of other races across all years and increased significantly by an average of $0.6 \%$ (95\% CI, 0.2 to $1.1 \%, p=0.01$ ) annually during the years investigated (Fig. 1d, Table 2). There were no significant changes in incidence rates of non-Hispanic blacks, Hispanic population and API population (APC $0.2,95 \% \mathrm{CI},-0.8$ to 1.3 , $p=0.648$; APC $0.0,95 \% \mathrm{CI},-0.9$ to $0.8, p=0.923$; APC $0.7,95 \% \mathrm{CI},-0.6$ to $1.9, p=0.266$, respectively) (Fig. $1 \mathrm{~d}$, Table 2). APC of AIAN population was not calculated and the incidence trend is not shown in Fig. 1d due to insufficient sample size.

Figure 2a showed that the incidence rates did not change significantly in all the 5-year age groups (65-69 years, APC $0.3,95 \% \mathrm{CI},-0.2$ to $0.8, p=0.219 ; 70-74$ years, APC $0,95 \% \mathrm{CI},-0.6$ to $0.6, p=0.976$; $75-79$ years, APC $0.3,95 \% \mathrm{CI},-0.5$ to $1.0, p=0.482 ; 80-84$ years, APC $0.8,95 \% \mathrm{CI},-0.1$ to $1.7, p=0.092 ; 85+$ years, APC 0.6, $95 \% \mathrm{CI},-0.3$ to $1.5, p=0.186$ ) (Table 2 ).

\section{Incidence trends of elderly glioblastoma by histological type, tumor location and size}

There was a non-significantly increasing incidence trend of glioblastoma, NOS, which was the most common histological type (APC 0.3, 95\% CI, -0.1 to $0.7, p=$ 0.107 ) (Fig. 2b, Table 2). The absolute change in incidence rate of giant cell glioblastoma and gliosarcoma was moderate due to relatively low incidence (Fig. 2b, Table 2).

The incidence rates of supratentorial glioblastoma increased significantly from 2000 to 2004 (APC 5.1, 95\% CI, 0.3 to 10.2, $p=0.039$ ) and remained stable from 2004 to 2017 (APC 0, 95\% CI, -0.6 to $0.7, p=0.899$ ), resulting in a significantly increasing trend of incidence across the years studied (APC 0.7, 95\% CI, 0.2 to $1.3, p$ 
Table 2 Trends of glioblastoma incidence in the elderly population: The SEER 18 registry database, 2000-201

\begin{tabular}{|c|c|c|c|}
\hline Characteristics & Period & APC $(95 \% \mathrm{Cl})$ & $\mathbf{P}$ \\
\hline Overall & $2000-2017$ & $0.3(-0.1,0.7)$ & 0.111 \\
\hline \multicolumn{4}{|l|}{ Gender } \\
\hline Male & 2000-2017 & $0.2(-0.2,0.6)$ & 0.272 \\
\hline Female & 2000-2017 & $0.2(-0.4,0.8)$ & 0.402 \\
\hline \multicolumn{4}{|l|}{ Race } \\
\hline Non-Hispanic White & 2000-2017 & $0.6(0.2,1.1)$ & $0.013^{c}$ \\
\hline Non-Hispanic Black & 2000-2017 & $0.2(-0.8,1.3)$ & 0.648 \\
\hline Hispanic & 2000-2017 & $0.0(-0.9,0.8)$ & 0.923 \\
\hline API & $2001-2017$ & $0.7(-0.6,1.9)$ & 0.266 \\
\hline \multicolumn{4}{|l|}{ Age at diagnosis, years } \\
\hline $65-69$ & 2000-2017 & $0.3(-0.2,0.8)$ & 0.219 \\
\hline $70-74$ & 2000-2017 & $0.0(-0.6,0.6)$ & 0.976 \\
\hline $75-79$ & 2000-2017 & $0.3(-0.5,1.0)$ & 0.482 \\
\hline $80-84$ & 2000-2017 & $0.8(-0.1,1.7)$ & 0.092 \\
\hline$\geq 85$ & 2000-2017 & $0.6(-0.3,1.4)$ & 0.186 \\
\hline \multicolumn{4}{|l|}{ Histologic type } \\
\hline Glioblastoma, NOS & 2000-2017 & $0.3(-0.1,0.7)$ & 0.107 \\
\hline Giant cell glioblastoma & 2000-2017 & $-2.3(-6.1,1.7)$ & 0.239 \\
\hline Gliosarcoma & 2000-2017 & $1.2(-1.0,3.4)$ & 0.264 \\
\hline \multicolumn{4}{|l|}{ Tumor location } \\
\hline Supratentorial & 2000-2017 & $0.7(0.2,1.3)$ & $0.016^{c}$ \\
\hline Supratentorial $\left.\right|^{a}$ & 2000-2004 & $5.1(0.3,10.2)$ & $0.039^{c}$ \\
\hline Supratentorial ${ }^{a}$ & 2004-2017 & $0.0(-0.6,0.7)$ & 0.899 \\
\hline Frontal & 2000-2017 & $1.7(1.0,2.5)$ & $<0.001^{c}$ \\
\hline Temporal & 2000-2017 & $0.9(0.3,1.6)$ & $0.010^{c}$ \\
\hline Parietal & 2000-2017 & $-0.7(-1.3,0.0)$ & 0.060 \\
\hline Occipital & 2000-2017 & $-0.4(-1.7,0.9)$ & 0.494 \\
\hline Infratentorial & 2000-2017 & $-0.4(-3.3,2.5)$ & 0.750 \\
\hline Overlapping/NOS & $2000-2017$ & $-0.9(-1.6,-0.2)$ & $0.012^{c}$ \\
\hline \multicolumn{4}{|l|}{ Tumor size, $\mathrm{cm}^{\mathrm{b}}$} \\
\hline$<4$ & 2004-2015 & $2.5(1.4,3.6)$ & $<0.001^{\mathrm{c}}$ \\
\hline$\geq 4$ & 2004-2015 & $0.8(0.0,1.6)$ & 0.057 \\
\hline Unknown & 2004-2015 & $-4.9(-6.6,-3.3)$ & $<0.001^{c}$ \\
\hline
\end{tabular}

Abbreviations: $A P C$ annual percentage change, $C l$ confidence interval, $A P I$ Asian/Pacific Islander, NOS not otherwise specified

${ }^{\text {a }}$ A statistically significant change in the APC was observed after join-point analysis

${ }^{b}$ Data are only documented between 2004 and 2015

c Statistically significant

$=0.016)$ (Fig. 2c, Table 2). APC of incidence for infratentorial glioblastoma was $-0.4(95 \% \mathrm{CI},-3.3$ to $2.5, p$ $=0.750$ ) (Fig. 2c, Table 2). A significantly decreasing trend of incidence was observed for overlapping/NOS glioblastoma (APC $-0.9,95 \% \mathrm{CI},-1.6$ to $-0.2, p=$ 0.012) (Fig. 2c, Table 2). Among supratentorial glioblastoma, incidences increased significantly for tumors located at frontal lobe and temporal lobe (APC 1.7, 95\% $\mathrm{CI}, 1.0$ to $2.5, p<0.001$; APC $0.9,95 \% \mathrm{CI}, 0.3$ to $1.6, p=$ 0.010 , respectively) (Fig. 2c, Table 2). There is a nonsignificantly decreasing tendency for tumors located at parietal lobe and occipital lobe (APC $-0.7,95 \% \mathrm{CI},-1.3$ to $0, p=0.060$; APC $-0.4,95 \% \mathrm{CI},-1.7$ to $0.9, p=0.494$, respectively) (Fig. 2c, Table 2).

When stratifying the incidence of elderly glioblastoma by tumor size, incidence of cases with a tumor smaller than $4 \mathrm{~cm}$ increased significantly from 3.44 per 100,000 population ( $95 \% \mathrm{CI}, 3.07-3.84$ ) in 2004 to 4.72 per 100 , 000 population (95\% CI, 4.34-5.13) in 2015 (APC 2.5, 95\% CI, 1.4 to $3.6, \mathrm{p}<0.001$ ) (Fig. $2 \mathrm{~d}$, Table 2). There was a non-significant increasing tendency for glioblastomas $\geq 4 \mathrm{~cm}$ (APC 0.8, $95 \mathrm{CI}, 0$ to $1.6, p=0.057$ ) (Fig. $2 \mathrm{~d}$, Table 2). The incidence of glioblastomas with unknown tumor sizes, however, decreased significantly from 2004 to 2015 (APC -4.9, 95\% CI, -6.6 to $-3.3, \mathrm{p}<$ 0.001) (Fig. 2d, Table 2).

\section{Age-period-cohort analysis}

The age-period-cohort modelling showed the effect of age on incidence trends $(p<0.001$, Wald test), while did not indicate the period and cohort effects of the incidence trends of glioblastoma ( $p=0.063$ and $p=0.536$, respectively, Wald test). The longitudinal age curve is displayed in Fig. 3a. The risk of glioblastoma increased with age from 65 to 66 years (10.589 per 100,000, 95\% CI, $9.9-11.326)$ to $77-78$ years ( 15.559 per $100,000,95 \%$ CI, 14.46-16.535), and for patients older than 78 years, the risk decreased with age and was lowest in patients aged over 85 years $(9.528$ per 100,000 , 95\% CI, 8.89210.21). The period and cohort effects on glioblastoma are displayed in Fig. 3b and Fig. 3c. The relative risks remained relatively stable for both periods and birth cohorts. Figure $3 \mathrm{~d}$ demonstrates the local drift values, which is the analog of the age-specific APC within the period studied. The overall net drift of $0.3 \%$ per year (95\% CI, 0.1-0.6\%) was quite modest. The local drifts were all above 0 and were higher with advanced age, which peaked at $0.7 \%$ per year $(95 \% \mathrm{CI}, 0.1-1.5 \%)$ in patients aged over 85 years.

\section{Discussion}

This review of the SEER 18 registry database with a 18year study period found that the age-adjusted incidence of glioblastoma in the elderly was 13.16 per 100,000 population, which is approximately 4 times higher than the overall incidence of glioblastoma according to the latest CBTRUS statistical report [1]. In contrast with previous work reporting an increasing trend of elderly glioblastoma, the overall age-adjusted incidence of glioblastoma in the elderly population was stable in recent years according to this study $[8,9]$. This discrepancy is likely due to shorter 


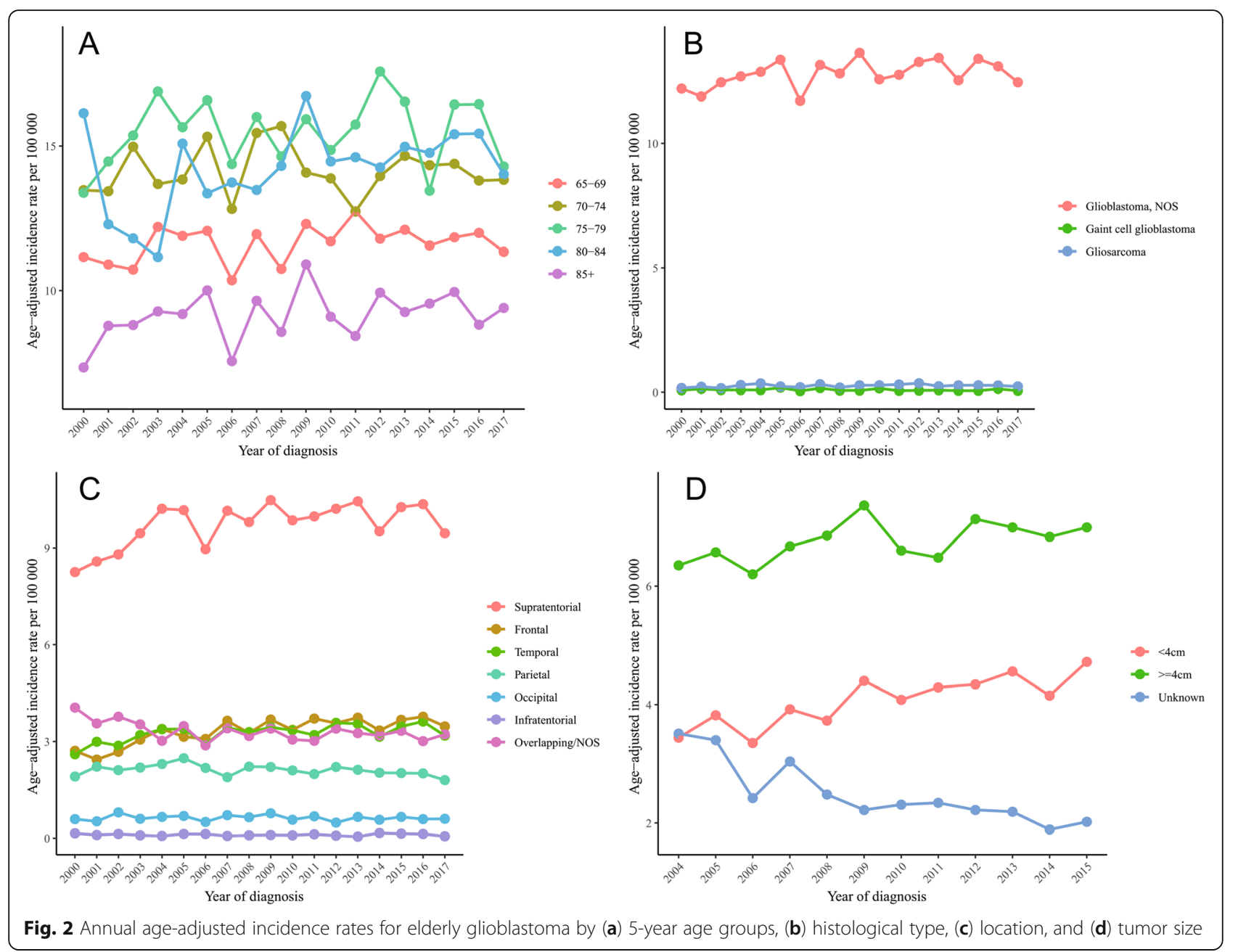

study periods in previous reports along with dissimilar ancestry of populations. In addition, we found the incidence of most subgroups did not change significantly except for non-Hispanic white population, supratentorial location (mostly attributed to frontal and temporal lobes), smaller tumor size $(<4 \mathrm{~cm})$, which increased significantly, and overlapping/NOS location, unknown tumor size, which declined significantly. The age-period-cohort analysis showed age effects on the trend of glioblastoma while did not show period and cohort effects on the incidence trend.

The incidence of glioblastoma varies in different age groups. Unlike meningioma, whose incidence tended to persistently increase in the oldest age group, the incidence of glioblastoma peaked in the age group of 75 to 79 years and then declined in 80-84 and 85+ years age groups [13]. This was also validated in the age-periodcohort analysis. Global life expectancy was forecasted to potentially increase to 77.8 years for males and 82.5 years for females in 2040 [14]. With the growing and aging population, glioblastoma, primarily a disease of the elderly with poor prognosis, should set alarm bells ringing.
Males were more frequently affected than females by most histological types of primary brain or other central nervous system tumors, including astrocytoma, oligodendroglioma, oligoastrocytic tumors, ependymal tumors, embryonal tumors, lymphoma, and germ cell tumors [1]. This study reported a glioblastoma Male: Female IRR of 1.62 among elderly patients, which is in consistence with previous work. We also identified a significant male predominance for every five-year age group. The sexual difference of glioblastoma incidence cannot be solely explained by the effect of acute sex hormone action due to the similar distribution among different age groups $[15,16]$. Molecular subtype-specific effects of incidence were reported in different subtypes of glioblastoma [16-19]. The Mesenchymal subtype with a combination of loss of NF1, PTEN, and TP53 function had the greatest Male: Female IRR of about 2:1 [18]. While the Classical subtype with EGFR mutation/amplification and CDKN2A deletion occurred equally in males and females [16]. However, due to the limitations for SEER-derived data, this study was unable to evaluate 


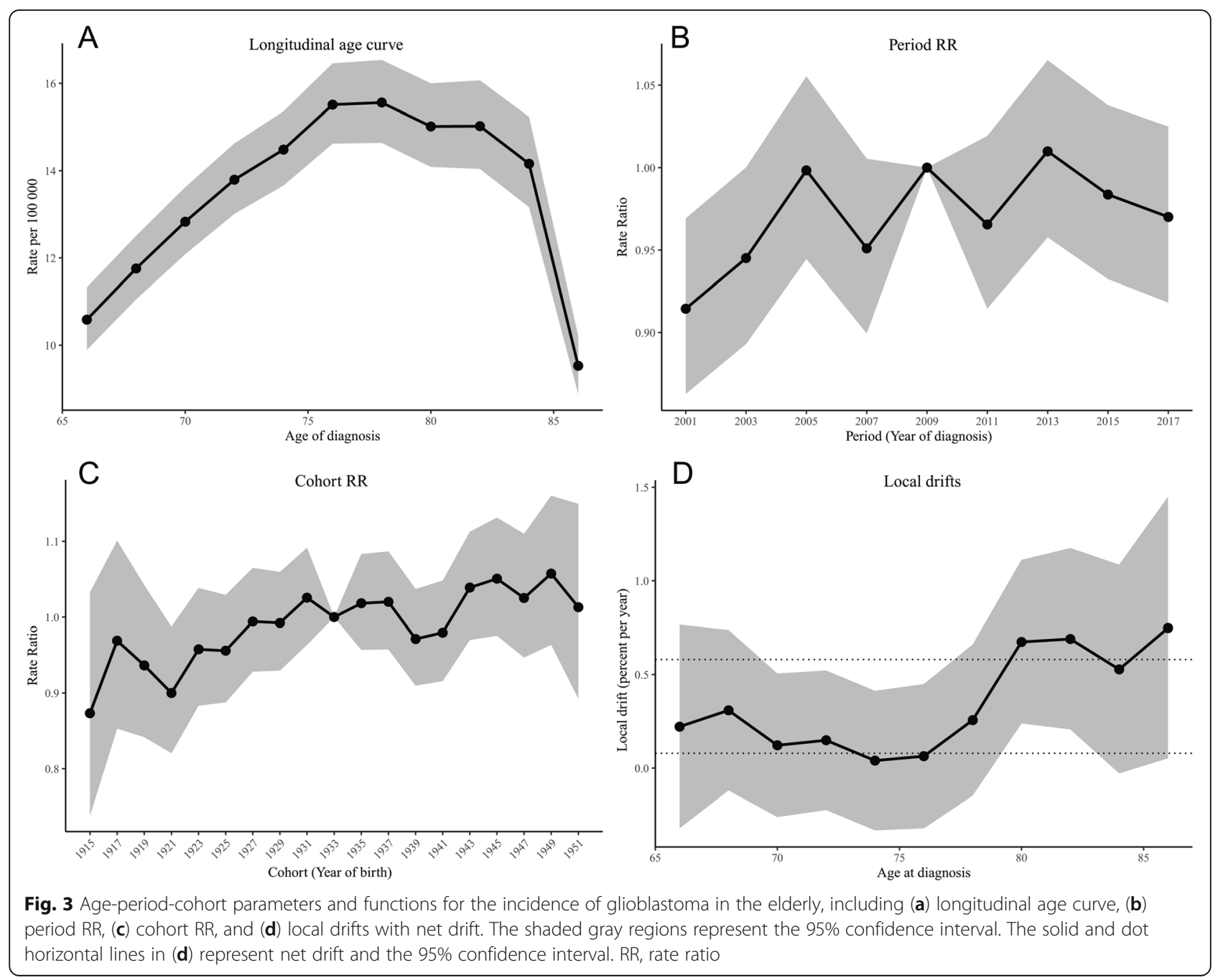

the difference in incidence by molecular subgroup. Further studies exploring sex differences in molecular mechanisms are required. Additionally, fetal microchimerism, which develops from the fetal cells transferred through the placenta to mothers during pregnancy and may remain a lifelong time, was found in approximately $80 \%$ female glioblastoma cases [20]. However, no specific clinical or molecular characteristics of glioblastoma was identified to associate with fetal microchimerism [20].

Like other gliomas, the incidence of glioblastoma was higher in non-Hispanic white population than any other race [21]. Glioblastoma incidence was also highest in regions with majority white populations, including North Europe and Canada [22]. Of noting, non-Hispanic white population was the only race subgroup that had an increasing trend of glioblastoma incidence. The root of this disparity may be partly attributed to the variance of hereditary susceptibility between races. A genome-wide association study suggested that increased European ancestry in non-European population might be associated with the occurrence of glioma and identified four novel susceptibility variants, including 7q21.11 (SEMA3A), 11p11.12 (Intergenic), 12q24.21 (RBM19) and 20p12.13 (HAO1, BMP2) [23]. Researchers have identified specific hereditary syndromes, such as Lynch and Li-Fraumeni, that are risk factors of glioma, although these diseases are rare [24]. This disparity may also partly due to the unequal chance of access to high-column hospitals for different races, thus non-whites which had worse access compared with whites might be misdiagnosed or underdiagnosed more frequently [25].

Most glioblastomas located above the tentorium cerebelli. Among these tumors, they were found to occur more commonly in frontal lobe and temporal lobe. There was an increasing incidence trend of supratentorial glioblastoma, which was mostly attributed to the two lobes mentioned above. It was reported that isocitrate dehydrogenase (IDH) mutant glioblastoma, which represents a minority of patients with glioblastoma (approximately $10 \%$ ) and is more commonly diagnosed in 
younger patients, preferentially locates at frontal lobe $[26,27]$. There was possibility that the increased incidence of frontal glioblastoma was partly attributed to the changes of molecular subtypes among elderly population. However, as data of IDH mutation are not documented in SEER database, we are unable to explore the incidence trend of IDH-wild and IDH-mutant glioblastoma. Further research into this hypothesis is warranted.

We also identified an increasing glioblastoma incidence trend of smaller tumor size $(<4 \mathrm{~cm})$ in the elderly population. This might be attributed to the advances in neuroimaging which facilitates early detection. However, this cannot explain the relatively stable overall glioblastoma incidence. Additionally, the quality of collection and record of cases in SEER registry database has improved, resulting in a decreasing incidence trend of unknown tumor size.

Period and cohort effects are interpreted as risk factors or changes of diagnostic criteria or disease classification that may affect all ages equally or differently $[12,28,29]$. The age-period-cohort analysis of this study did not show period and cohort effects on the incidence trend of glioblastoma. Accumulating evidence have suggested that environmental factors are thought to be responsible for the occurrence of tumors [30]. However, there are only few validated environmental risk factors for glioblastoma. Ionizing radiation exposure is the only and modifiable environmental factor that facilitates glioblastoma development [31, 32]. A retrospective cohort study found a positive association between exposure to computed tomography and glioma with an excessive relative risk per mGy of $0.019(p=0.0033)$, although it recruited only children and the overall incidence remained low [33]. The association between usage of cell phone and glioma has caught attention. However, various reports have drawn inconsistent conclusions regarding the relationship between cell phone exposure and the development of glioma [34-37]. However, the result of age-period-cohort analysis may suggest that these factors had little effect on the incidence of glioblastoma in the elderly.

Davis et al. addressed several data-driven factors such as data collection practices and changes of WHO classification that have influenced the patterns of incidence trends of glioblastoma in England, Canada and the United States [38]. Misclassification of tumors by histology is less likely to happen in recent years due to improved accuracy of histological category and standardized data collection procedure in the United States. The stable incidence trend of elderly glioblastoma in this study can somehow reflect that data-driven factors have little effect on the incidence in recent years and in the United States.
There are some limitations that should be acknowledged. First, our analysis was based on the SEER 18 registry database, which only covers approximately $28 \%$ of the US population. The results of this study cannot represent the whole US population, despite high-quality collection and record of cases. Second, as discussed above, the molecular subtypes of glioblastoma are not specified in SEER database. The good news is that molecular information has been collected by the Central Cancer Registry in the United States since January 1, 2018 [1]. Future studies focusing on the incidence trends of specific molecular subtypes will further our understanding of glioblastoma. Third, data of the glioblastoma incidence were retrospectively collected, thus we were only able to comprehensively describe the trend of incidence. The underlying factors that may contribute to the trend were interpreted on speculation.

\section{Conclusion}

In summary, the overall incidence of glioblastoma in the elderly population remained stable between 2000 and 2017. Male, non-Hispanic white predominance was observed, in accordance with previous reports. There was an increasing incidence trend of glioblastoma for nonHispanic white race, supratentorial location, and smaller tumor size $(<4 \mathrm{~cm})$ and a decreasing trend for overlapping/NOS location and unknown tumor size. Period and cohort effects were not evident in the trend of glioblastoma incidence. Future population-based studies exploring the difference in the trend of glioblastoma incidence by specific molecular subgroups are warranted to further our understanding of the etiology of glioblastoma.

\section{Abbreviations}

APC: Annual percentage change; CBTRUS: Central Brain Tumor Registry of the United States; SEER: Surveillance Epidemiology and End Results; ICD-O3: International Classification of Diseases for Oncology, Third Edition; API: Asian/Pacific Islander; AIAN: American Indian/Alaskan Native; IRR: Incidence rate ratio; NOS: Not otherwise specified; IDH: Isocitrate dehydrogenase

Acknowledgements

We would like to thank SEER program for providing free access to its data.

\section{Authors' contributions}

Study concept and design: BC and CC. Data collection, analysis and interpretation: BC, CC, and YZ. Figures and tables: BC. Manuscript drafting: BC and CC. Manuscript revision: $Y Z$ and JX. The author(s) read and approved the final manuscript.

\section{Funding}

This study was supported by 1.3.5 Project for Disciplines of Excellence, West China Hospital, Sichuan University (ZYJC18007). The funder did not participant in the study concept, design, data collection, analysis, interpretation, or manuscript drafting.

Availability of data and materials

Data analyzed in this study was derived from SEER database (https://seer. cancer.gov/). 


\section{Ethics approval and consent to participate}

Not applicable. (This is a SEER database-based retrospective study. We signed a SEER Research Data Use Agreement form and gained access to data in SEER database. There is no need for SEER database-based study to obtain informed consent.)

\section{Consent for publication}

Not applicable.

\section{Competing interests}

The authors declare that they have no competing interests.

\section{Author details}

'Department of Neurosurgery, West China Hospital, Sichuan University, West China Hosptial, No. 37, GuoXue Alley, Chengdu 610041, People's Republic of China. ${ }^{2}$ West China School of Medicine, Sichuan University, Chengdu, China. ${ }^{3}$ State Key Laboratory of Biotherapy and Cancer Center, West China Hospital, Sichuan University, and Collaborative Innovation Center for Biotherapy, Chengdu, China.

\section{Received: 28 September 2020 Accepted: 28 December 2020}

Published online: 12 January 2021

\section{References}

1. Ostrom Q, Cioffi G, Gittleman H, Patil N, Waite K, Kruchko C. Barnholtz-Sloan JJN-o: CBTRUS Statistical Report: Primary Brain and Other Central Nervous System Tumors Diagnosed in the United States in 2012-2016. Neuro-Oncol. 2019;21:v1-v100.

2. Ostrom QT, Gittleman H, Truitt G, Boscia A, Kruchko C, Barnholtz-Sloan JS. CBTRUS Statistical Report: Primary Brain and Other Central Nervous System Tumors Diagnosed in the United States in 2011-2015. Neuro-Oncol. 2018; 20(suppl_4):iv1-iv86.

3. Paszat L, Laperriere N, Groome P, Schulze K, Mackillop W, Holowaty E. A population-based study of glioblastoma multiforme. Int J Radiat Oncol Biol Phys. 2001;51(1):100-7.

4. Stupp R, Mason WP, van den Bent MJ, Weller M, Fisher B, Taphoorn MJ, Belanger K, Brandes AA, Marosi C, Bogdahn U, et al. Radiotherapy plus concomitant and adjuvant temozolomide for glioblastoma. New England J Med. 2005;352(10):987-96.

5. Lamborn KR, Chang SM, Prados MD. Prognostic factors for survival of patients with glioblastoma: recursive partitioning analysis. Neuro-Oncol. 2004;6(3):227-35.

6. Lacroix M, Abi-Said D, Fourney DR, Gokaslan ZL, Shi W, DeMonte F, Lang FF, McCutcheon IE, Hassenbusch SJ, Holland E, et al. A multivariate analysis of 416 patients with glioblastoma multiforme: prognosis, extent of resection, and survival. J Neurosurg. 2001;95(2):190-8.

7. Perry JR, Laperriere N, O'Callaghan CJ, Brandes AA, Menten J, Phillips C, Fay M, Nishikawa R, Cairncross JG, Roa W, et al. Short-Course Radiation plus Temozolomide in Elderly Patients with Glioblastoma. New England J Med. 2017;376(11):1027-37.

8. Dobes M, Khurana VG, Shadbolt B, Jain S, Smith SF, Smee R, Dexter M, Cook R. Increasing incidence of glioblastoma multiforme and meningioma, and decreasing incidence of Schwannoma (2000-2008): Findings of a multicenter Australian study. Surg Neurol Int. 2011:2:176.

9. Korja M, Raj R, Seppä K, Luostarinen T, Malila N, Seppälä M, Mäenpää H, Pitkäniemi J. Glioblastoma survival is improving despite increasing incidence rates: a nationwide study between 2000 and 2013 in Finland. Neuro-Oncol. 2019;21(3):370-9.

10. Kim HJ, Fay MP, Feuer EJ, Midthune DN. Permutation tests for joinpoint regression with applications to cancer rates. Stat Med. 2000;19(3):335-51.

11. Rosenberg PS, Check DP, Anderson WF. A web tool for age-period-cohort analysis of cancer incidence and mortality rates. Cancer Epidemiol Biomarkers Prev. 2014:23(11):2296-302.

12. Li K, Lu D, Guo Y, Wang C, Liu X, Liu Y, Liu D. Trends and patterns of incidence of diffuse glioma in adults in the United States, 1973-2014. Cancer Med. 2018;7(10):5281-90.

13. Achey RL, Gittleman H, Schroer J, Khanna V, Kruchko C, Barnholtz-Sloan JS. Nonmalignant and malignant meningioma incidence and survival in the elderly, 2005-2015, using the Central Brain Tumor Registry of the United States. Neuro-oncology. 2019;21(3):380-91.
14. Foreman KJ, Marquez N, Dolgert A, Fukutaki K, Fullman N, McGaughey M, Pletcher MA, Smith AE, Tang K, Yuan CW, et al. Forecasting life expectancy, years of life lost, and all-cause and cause-specific mortality for 250 causes of death: reference and alternative scenarios for 2016-40 for 195 countries and territories. Lancet (London, England). 2018;392(10159):2052-90.

15. Ober C, Loisel DA, Gilad Y. Sex-specific genetic architecture of human disease. Nat Rev Genet. 2008;9(12):911-22.

16. Sun T, Plutynski $A$, Ward $S$, Rubin JB. An integrative view on sex differences in brain tumors. Cell Mol Life Sci. 2015;72(17):3323-42.

17. Phillips HS, Kharbanda S, Chen R, Forrest WF, Soriano RH, Wu TD, Misra A, Nigro JM, Colman H, Soroceanu L, et al. Molecular subclasses of high-grade glioma predict prognosis, delineate a pattern of disease progression, and resemble stages in neurogenesis. Cancer Cell. 2006;9(3):157-73.

18. Sun T, Warrington NM, Luo J, Brooks MD, Dahiya S, Snyder SC, Sengupta R, Rubin JB. Sexually dimorphic RB inactivation underlies mesenchymal glioblastoma prevalence in males. J Clin Invest. 2014;124(9):4123-33.

19. Verhaak RG, Hoadley KA, Purdom E, Wang V, Qi Y, Wilkerson MD, Miller CR, Ding L, Golub T, Mesirov JP, et al. Integrated genomic analysis identifies clinically relevant subtypes of glioblastoma characterized by abnormalities in PDGFRA, IDH1, EGFR, and NF1. Cancer Cell. 2010;17(1):98-110.

20. Broestl L, Rubin JB, Dahiya S. Fetal microchimerism in human brain tumors. Brain Pathol. 2018:28(4):484-94.

21. Ostrom Q, Cote D, Ascha M, Kruchko C, JJJo B-S. Adult Glioma Incidence and Survival by Race or Ethnicity in the United States From 2000 to 2014. JAMA Oncol. 2018;4(9):1254-62.

22. Leece R, Xu J, Ostrom Q, Chen Y, Kruchko C, JJN-o B-S. Global incidence of malignant brain and other central nervous system tumors by histology, 2003-2007. Neuro-oncology. 2017;19(11):1553-64.

23. Ostrom QT, Egan KM, Nabors LB, Gerke T, Thompson RC, Olson JJ, LaRocca R, Chowdhary S, Eckel-Passow JE, Armstrong G, et al. Glioma risk associated with extent of estimated European genetic ancestry in African Americans and Hispanics. Int J Cancer. 2020;146(3):739-48.

24. Scheurer ME, Etzel CJ, Liu M, Barnholtz-Sloan J, Wiklund F, Tavelin B, Wrensch MR, Melin BS, Bondy ML. Familial aggregation of glioma: a pooled analysis. Am J Epidemiol. 2010;172(10):1099-107.

25. Mukherjee D, Zaidi HA, Kosztowski T, Chaichana KL, Brem H, Chang DC, Quiñones-Hinojosa A. Disparities in access to neuro-oncologic care in the United States. Archives Surgery. 2010;145(3):247-53.

26. Ohgaki $H$, Kleihues $P$. The definition of primary and secondary glioblastoma. Clin Cancer Res. 2013;19(4):764-72

27. Tan AC, Ashley DM, López GY, Malinzak M, Friedman HS, Khasraw M. Management of glioblastoma: State of the art and future directions. CA Cancer J Clin. 2020;70(4):299-312.

28. Holford TR. Understanding the effects of age, period, and cohort on incidence and mortality rates. Annu Rev Public Health. 1991;12:425-57.

29. Keyes KM, Utz RL, Robinson W, Li G. What is a cohort effect? Comparison of three statistical methods for modeling cohort effects in obesity prevalence in the United States, 1971-2006. Soc Sci Med. 2010;70(7):1100-8.

30. Tiffon C. The Impact of Nutrition and Environmental Epigenetics on Human Health and Disease. Int J Mol Sci. 2018;19(11).

31. Fisher JL, Schwartzbaum JA, Wrensch M, Wiemels JL. Epidemiology of brain tumors. Neurol Clin. 2007;25(4):867-90 vii.

32. Omuro A, DeAngelis LM. Glioblastoma and other malignant gliomas: a clinical review. Jama. 2013;310(17):1842-50.

33. Pearce MS, Salotti JA, Little MP, McHugh K, Lee C, Kim KP, Howe NL, Ronckers CM, Rajaraman P, Sir Craft AW, et al. Radiation exposure from CT scans in childhood and subsequent risk of leukaemia and brain tumours: a retrospective cohort study. Lancet (London, England). 2012;380(9840):499505.

34. Corle C, Makale M, Kesari S. Cell phones and glioma risk: a review of the evidence. J Neurooncol. 2012;106(1):1-13.

35. Deltour I, Auvinen A, Feychting M, Johansen C, Klaeboe L, Sankila R, Schüz J. Mobile phone use and incidence of glioma in the Nordic countries 19792008: consistency check. Epidimiology. 2012;23(2):301-7.

36. Hardell L, Carlberg M, Hansson Mild K. Use of mobile phones and cordless phones is associated with increased risk for glioma and acoustic neuroma. Pathophysiology: the official journal of the International Society for. Pathophysiology. 2013:20(2):85-110.

37. Little MP, Rajaraman P, Curtis RE, Devesa SS, Inskip PD, Check DP, Linet MS. Mobile phone use and glioma risk: comparison of epidemiological study results with incidence trends in the United States. BMJ. 2012;344:e1147. 
38. Davis FG, Smith TR, Gittleman HR, Ostrom QT, Kruchko C, Barnholtz-Sloan JS Glioblastoma incidence rate trends in Canada and the United States compared with England, 1995-2015. Neuro-Oncol. 2020;22(2):301-2.

\section{Publisher's Note}

Springer Nature remains neutral with regard to jurisdictional claims in published maps and institutional affiliations.

Ready to submit your research? Choose BMC and benefit from:

- fast, convenient online submission

- thorough peer review by experienced researchers in your field

- rapid publication on acceptance

- support for research data, including large and complex data types

- gold Open Access which fosters wider collaboration and increased citations

- maximum visibility for your research: over $100 \mathrm{M}$ website views per year

At $\mathrm{BMC}$, research is always in progress. 